\title{
Using a Kinase/Phosphatase Switch to Regulate a Supramolecular Hydrogel and Forming the Supramolecular Hydrogel in vivo
}

\author{
Zhimou Yang, Gaolin Liang, Ling Wang, Bing Xu*
}

Supporting Information

General. Chemical reagents and solvents were used as received from commercial sources. ${ }^{1} \mathrm{HNMR}$ spectra were obtained on a 300 MHz Varian XL-300 using DMSO- $\mathrm{d}_{6}$ as the solvent; Mass spectra were measured on Finnigan TSQ7000 System; circular dichroism spectra were taken on a JASCO J-810 spectropolarimeter; emission spectra were recorded on a Perkin-Elmer LS-55 luminance spectrometer; HPLC analysis were performed on Waters 600E Multi-solvent Delivery System using XTerra MS $\mathrm{C}_{18} \mathrm{RP}$ column with $\mathrm{CH}_{3} \mathrm{CN}(0.1 \%$ of TFA) and water $(0.1 \%$ of TFA) as the eluent. Transmission electron micrograph (TEM) was done on JEOL 2010 transmission electron microscope, operating at $200 \mathrm{kV}$. Rheology test was performed on Rheometrics ARES with a cone and plate (25 $\mathrm{mm}$ diameter plate and 0.0999 rad cone angle). The cryo-dried samples were prepared as following: a copper grid coated with carbon was dipped into the hydrogel and placed into a vial, which was plunged into liquid nitrogen. Then, water was removed from the frozen specimen by a freeze-drier.

Buffer. Water solution with $\mathrm{pH}=7.4$ and containing $0.1 \mathrm{mg} / \mathrm{mL}$ of bovine serum albumin (BSA), $20 \mathrm{mM}$ $\mathrm{N}$-(2-hydroxyethyl)-piperazine-N'-2-ethanesulfonic acid (HEPES), $2 \mathrm{mM}$ of dithiothreitol (DTT), $1.25 \mathrm{mM}$ of $\mathrm{CaCl}_{2}, 10 \mathrm{mM}$ of $\mathrm{MgCl}_{2}, 10 \mathrm{mM}$ of ATP.

Enzymes. Tyrosine kinase: $1 \mathrm{U}=1 \mathrm{nmol}$ of phosphate group transferring from ATP to poly(Glu-Tyr)/minute. Alkali phosphatase: $1 \mathrm{U}=$ cleaving $1 \mu \mathrm{mol}$ of phosphate group from 4-nitrophenyl phosphate/minute.

Rheology experiment. $0.6 \mathrm{~mL}$ of the gel I was sandwiched between the cone plates to obtain the strain curve at the frequency of $1.0 \mathrm{rad} / \mathrm{s} .0 .6 \mathrm{~mL}$ of the gel I was sandwiched between the cone plates to obtain the frequency curve at the strain of $0.8 \%$. The solution containing $1.8 \mathrm{mg}$ of $1,1.9 \mathrm{mg}$ of 2 and $12 \mu \mathrm{L}(400 \mathrm{U} / \mathrm{mL})$ of alkali phosphatase in $0.6 \mathrm{~mL}$ buffer was sandwiched between the cone plate at the strain of $0.8 \%$ and the frequency of $1 \mathrm{rad} / \mathrm{s}$ for dynamic time sweep experiment. All rheological measurements are carried out at room temperature, and the gap opening at the apex of the cone and plate was set to $0.0483 \mathrm{~mm}$.

Cytotoxicity test. HeLa cells were seeded into a 96-well plate at a concentration of $3 \times 10^{3}$ cells/well in $100 \mu \mathrm{L}$ MEM medium with 10\% FBS. Compounds 1 and 2 at 125, 250, and $500 \mu \mathrm{M}$, respectively, were added when cells were plated. Then, the cell cultures were incubated for 2 days at $37{ }^{\circ} \mathrm{C}$ and $5 \% \mathrm{CO}_{2}$. MTT assay was carried out every 24 hours to measure the proliferation of HeLa cells.

Animal test. Animal studies were conducted with the approval of the Institutional Animal Care and Use Committee. All mice were supplied by the Animal and Plant Care Facility (APCF) of The Hong Kong University of Science \& Technology. The strain of the mice is Balb/c, male, 7 weeks old, mean body weight $=$ 20 grams. $0.5 \mathrm{~mL}$ of solution of $0.8 \mathrm{wt} \%$ of 2 was injected into each mouse subcutaneously or intraperitoneally 
(the mice were anaesthetized so that pain was maximally reduced during experiments). One hour after the injection, the mouse was sacrificed and the injection part was cut to show whether the gelation occurred. Twenty-four mice were used in the experiment to determine the in vivo toxicity of 2 after i.p. and subcutaneous administration. All animals were divided into 4 groups at random and weighed as the date of day 0. Group I received $0.5 \mathrm{~mL}$ of solution of $0.8 \mathrm{wt} \%$ of 2 intraperitoneally after being anesthetized. Group II received $0.5 \mathrm{~mL}$ of saline and served as control for i.p. injection. Group III were subcutaneously administered $0.5 \mathrm{~mL}$ of solution of $0.8 \mathrm{wt} \%$ of 2 after being anesthetized. Group IV subcutaneously received $0.5 \mathrm{~mL}$ of saline and served as the control for s.c. injection. The body weights of the mice were recorded every 24 hours until the day 7.

Synthesis: Nap-FFGEY (1) and Nap-FFGEY-P(O)(OH) 2 (2) were prepared by solid phase synthesis using 2-chlorotrityl resin and the corresponding Fmoc- protected amino acids and purified with reverse phase HPLC using $\mathrm{CH}_{3} \mathrm{CN} / \mathrm{H}_{2} \mathrm{O}$ as the eluent.

${ }^{1} \mathrm{HNMR}$ of Nap-FFGEY (1) $\left(300 \mathrm{MHz}, \mathrm{DMSO}-d_{6}\right) \delta(\mathrm{ppm}): 9.38(\mathrm{~s}, 1 \mathrm{H}), 8.36-8.42(\mathrm{~m}, 4 \mathrm{H}), 8.08-8.11(\mathrm{~d}, 1 \mathrm{H})$, 8.00-8.03 (d, 1H), 7.89-7.95 (m, 2H), $7.74(\mathrm{~s}, 1 \mathrm{H}), 7.62-7.64(\mathrm{~m}, 2 \mathrm{H}), \quad 7.32-7.39(\mathrm{~m}, 11 \mathrm{H}), 7.16-7.19(\mathrm{~d}, 2 \mathrm{H})$, 6.80-6.82 (d, 2H), 4.68-4.72 (m, 2H), 4.47-4.54 (m, 2H), $3.90(\mathrm{~s}, 2 \mathrm{H}), 3.58-3.71(\mathrm{q}, 2 \mathrm{H}), 2.89-3.19(\mathrm{~m}, 6 \mathrm{H})$, 2.38-2.44 (t, 2H), 2.00-2.12 (m, 1H) and 1.86-1.98 (m, 1H). MS: calc. $\mathrm{M}^{+}=829.3$, obsvd. $(\mathrm{M}+1)^{+}=829.6$.

${ }^{1} \mathrm{HNMR}$ of Nap-FFGEY-P(O) $(\mathrm{OH})_{2}(2)\left(300 \mathrm{MHz}, \mathrm{D}_{2} \mathrm{O}\right) \delta(\mathrm{ppm}):$ 7.86-8.05 (m, 3H), 7.67 (s, 1H), 7.59-7.62 (m, $2 \mathrm{H}), 7.18-7.32(\mathrm{~m}, 6 \mathrm{H}), 7.12(\mathrm{~d}, 1 \mathrm{H}), 6.89-7.02(\mathrm{~d}, 1 \mathrm{H}), 6.66-6.68(\mathrm{~d}, 1 \mathrm{H}), 4.58-4.64(\mathrm{~m}, 2 \mathrm{H}), 4.37-4.41(\mathrm{t}, 1 \mathrm{H})$, 4.27-4.31 (q, 1H), 3.74-3.93 (q, 2H), $3.67(\mathrm{~s}, 1 \mathrm{H}), 2.85-3.22(\mathrm{~m}, 4 \mathrm{H}), 1.90-2.25(\mathrm{~m}, 2 \mathrm{H}) .{ }^{31} \mathrm{P}$ NMR $(300 \mathrm{MHz}$ $\left.\mathrm{D}_{2} \mathrm{O}\right) \delta(\mathrm{ppm}):-5.5375$. MS: calc. $\mathrm{M}^{+}=909.3$, obsvd. $(\mathrm{M}+1)^{+}=910.2,(\mathrm{M}+\mathrm{Na})^{+}=932.2$.

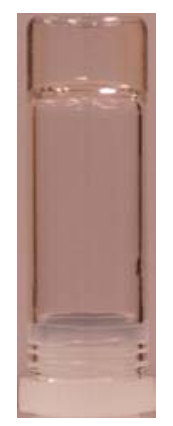

Figure $\boldsymbol{S}-1$. Optical image of the hydrogel of 1 in water $(0.6 \mathrm{wt} \%, \mathrm{pH}=7.4)$.

Table S-1. Eluting gradient for HPLC analysis of gel I, gel II, solution of $\mathbf{1}$ and solution of 2.

\begin{tabular}{|c|c|c|c|}
\hline Time (minute) & Flow (ml/min.) & $\mathrm{H}_{2} \mathrm{O} \%$ & $\mathrm{CH}_{3} \mathrm{CN} \%$ \\
\hline 0 & 5.0 & 60 & 40 \\
\hline 25 & 5.0 & 20 & 80 \\
\hline 60 & 5.0 & 60 & 40 \\
\hline 30 & 5.0 & 60 & 40 \\
\hline
\end{tabular}



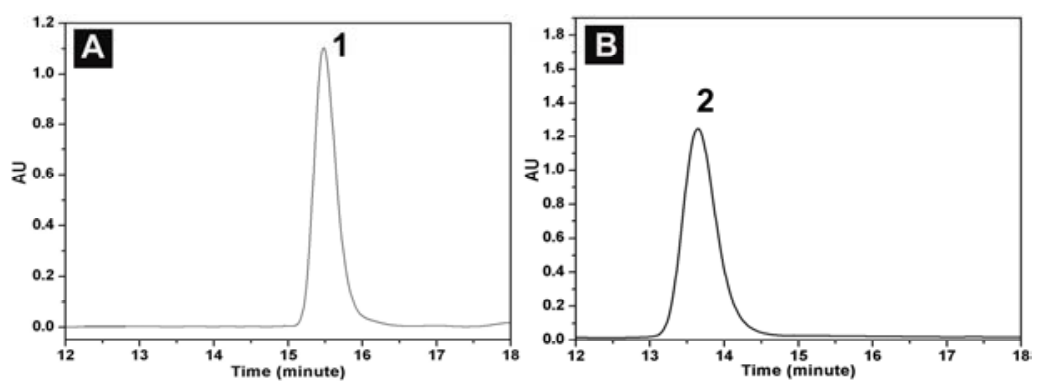

Figure S-2. HPLC trace of (A) solution of $\mathbf{1}$ and (B) solution of $\mathbf{2}$ by the methods described in Table $\boldsymbol{S}-\mathbf{1}$.

Table S-2. Eluting gradient for HPLC analysis of the hydrogel formed in vivo and the abdominal fluid

\begin{tabular}{|c|c|c|c|}
\hline Time (minute) & Flow (ml/min.) & $\mathrm{H}_{2} \mathrm{O} \%$ & $\mathrm{CH}_{3} \mathrm{CN} \%$ \\
\hline 0 & 5.0 & 80 & 20 \\
\hline 30 & 5.0 & 20 & 80 \\
\hline 31 & 5.0 & 0 & 100 \\
\hline 35 & 5.0 & 0 & 100 \\
\hline 36 & 5.0 & 80 & 20 \\
\hline 40 & 5.0 & 80 & 20 \\
\hline
\end{tabular}
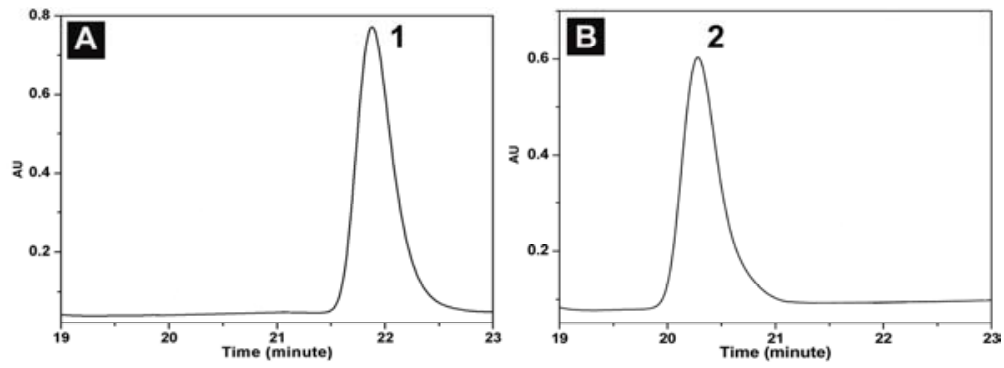

Figure S-3 HPLC trace of (A) solution of 1 and (B) solution of $\mathbf{2}$ by the methods described in Table $\boldsymbol{S}-\mathbf{2}$.

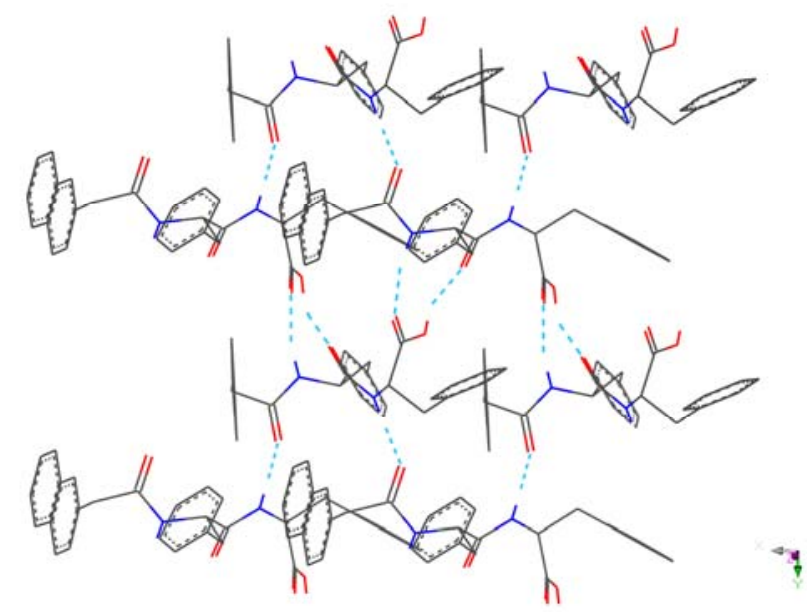

Figure $\boldsymbol{S}$-4. $\beta$-sheet-like molecular packing in the crystal structure of Nap-FF. 